\title{
Exploring the relationships of citizens' scientific interest and self-understanding to their learning enjoyment and self-efficacy in science
}

\author{
Ying-Yan Lu ${ }^{1}$. Thomas J. Smith ${ }^{2} \cdot$ Zuway-R. Hong ${ }^{1} \cdot$ Huann-shyang Lin ${ }^{3} \cdot$ Wen-Yi Hsu ${ }^{1}$ \\ Accepted: 23 January 2022 \\ ๑) The Author(s), under exclusive licence to Springer Science+Business Media, LLC, part of Springer Nature 2022
}

\begin{abstract}
The aim of this study was to explore whether citizens' scientific interest and self-understanding relate to their learning enjoyment and self-efficacy in science. The sample participants consisted of 1,657 Taiwanese citizens ranging from 18 to 70 years of age. All participants were asked to complete the 2018 "Taiwan Citizens Science and Technology Literacy Survey" to assess their scientific interest, scientific self-understanding, science learning enjoyment, and scientific self-efficacy. Multiple regression models were used to analyze the data. The important findings included: (1) scientific interest was the most important predictor of science learning enjoyment, while scientific self-understanding was the most important predictor of scientific selfefficacy; and (2) the effects of scientific interest on self-understanding and the effect of science learning enjoyment on scientific self-efficacy each were significantly moderated by respondents' age, with stronger relationships observed in younger citizens than older citizens. This study provides insight into Taiwanese citizens' scientific learning enjoyment and self-efficacy and also informs potential governmental policies and/or societal practices that could be considered to promote scientific literacy.
\end{abstract}

Keywords Science learning enjoyment $\cdot$ Scientific interest $\cdot$ Scientific self-efficacy $\cdot$ Scientific self-understanding ·

Taiwanese citizens

\section{Introduction}

Over the past decades, science education communities throughout the globe have been concerned about scientific literacy. Snow and Dibner (2016) point out that the contemporary definition of scientific literacy extends to the understanding of scientific matters, interest in scientific activities, ability to evaluate scientific conditions, and participation in discussions of science-related issues. Abilities like evaluating science information and discussion engagement are essential for citizens to participate in decision-making

Zuway-R. Hong

a3803429@gmail.com

1 Kaohsiung Medical University, Center for General Education, 100, Shih-Chuann 1st Road, Kaohsiung 80708, Taiwan

2 Department of Educational Technology, Research and Assessment, Northern Illinois University, DeKalb, IL, USA

3 National Sun Yat-Senen University, Center for General Education, Kaohsiung, Taiwan regarding both their daily lives and socio-scientific issues in public affairs (Bauer et al., 2007; Tsai et al., 2017). The importance of enhancing science literacy among citizens has become most increasingly apparent in the wake of the COVID-19 pandemic, where citizens' ability to critically evaluate information from diverse sources and to distinguish scientifically-based information from weakly-supported ideas, rumor, or conspiracy theories can have direct impact on community-led efforts to curb the spread of infection (Stein et al., 2021). However, the effects of scientific literacy also can have profound effects on other areas of public health, as well as on issues involving the environment and the economy (Rutjens et al., 2021; Van Bavel et al., 2020). Therefore, it is crucial for citizens to understand information related to science and technology issues and use scientific knowledge and skills to solve problems in their lives (Chin et al., 2016; Tsai et al., 2017). Citizen engagement in science is a life-long process. Previous research has documented that large numbers of people find science interesting enough to participate in science learning activities (Ballantyne \& Packer, 2009; Bell et al., 2009). Bell et al. (2009) point out that most people construct their understanding of science 
over the course of their lives, gathering information from many places and contexts for a variety of reasons. Falk et al. (2007) also argued that citizens' science learning happens within everyday life and is driven by their needs. Therefore, assessing citizens' generalized science understanding may not be a paramount priority. Instead, examining what factors affect citizens' engagement with science and how this engagement occurs are worthwhile to explore.

Attitude toward science is a crucial aspect that has an effect on citizens' scientific literacy [National Science Board, 2016; Organization for Economic Co-operation Development (OECD), 2017], and also might influence how citizens interact with science in their lives. Related studies have found that attitudes toward science have strong relationships with scientific literacy (e.g., Lin et al., 2013b; WoodsMcConney et al., 2014). Attitude involves citizens' beliefs toward some object of attention, including whether they like something, and their related experiences (Reid \& Ali, 2020). Falk et al. (2007) found that affective factors, such as one's interest in science issues, can motivate citizens' enjoyment in leisure science learning, while Corin et al. (2018) found that citizens' self-understanding of science issues can promote their engagement in science activities. Another factor that is relevant to how citizens deal with science issues, problems, or information they meet in their daily lives is self-efficacy-which refers to an individual's confidence in his or her ability to accomplish a specific task (Bandura, 1986, 1997; Hardin \& Longhurst, 2016; Porras-Hernández \& Salinas-Amescua, 2012).

From the discussion above, citizens' scientific interest and self-understanding pertaining to science issues may have an impact on their engagement in science activities which may relate to their attitude toward science learning such as enjoyment and self-efficacy. Wan and Lee (2017) explored how different attitudinal factors relate to each other, and their results show that when citizens have higher interest in science knowledge or science issues, they may show more inclination towards science program participation that may enhance their engagement and enjoyment in science. The authors also point out that citizens' selfunderstanding on science issues positively relates to their curiosity about scientific phenomena which may inspire them to read more science-related books, articles, magazines, and news sources, and prompt them to search for additional scientific information to identify answers and solve their problems (Bucchi \& Saracino, 2016). When citizens have more confidence in their ability to complete tasks, their self-efficacy may be increased. Thus, Oh et al. (2020) suggest that citizens' self-understanding of science issues will relate positively to scientific self-efficacy. Additionally, it is hypothesized that scientific interest and self-understanding may be related to science learning enjoyment and scientific self-efficacy (Lin et al., 2013a).
Furthermore, numerous studies have asserted that gender and age are important factors to consider when discussing science learning and engagement (Kelemen-Finan et al., 2018; Takahashi \& Tandoc, 2016). However, to date there is limited evidence examining whether gender and age might moderate effects of citizens' cognitive and affective attitude toward science issues on their scientific self-efficacy. Therefore, this research aims to examine data from a public context to assess how Taiwanese citizens' interest and self-understanding on science issues predict their learning enjoyment and scientific self-efficacy, and whether these relationships are moderated by gender and age.

\section{Theoretical Framework}

\section{Citizens' Attitude Toward Science}

The structure of scientific literacy in the Programme for International Student Assessment (PISA) 2015 framework (OECD, 2017) posits that, ultimately, citizens' science competencies are affected not only by their scientific knowledge, but also by their attitude toward science (OECD, 2017). However, scientific content knowledge is a commonly-discussed facet pertaining to citizens' scientific literacy (Meyer, 2016; Simis et al., 2016). Attitude toward science affects the extent to which citizens take part in science activities, deal with science information, or involve themselves in public scientific issues (Falk et al., 2007; Jones et al., 2017). Relatedly, Rose et al. (2019) found that citizens' attitude toward a socio-scientific issue is based more strongly on affective perception than on factual knowledge. Although attitude doesn't directly control citizens' behavior, it has powerful influence on behavior (Reid \& Ali, 2020); therefore, when confronting science issues, attitude - to a greater extent than factual knowledge-may be crucial to citizens' science involvement.

Attitude can be classified into three components: cognitive, affective, and behavioral. Cognitive attitude is related to what individuals know, such as beliefs or ideas; affective attitude is related to people's feelings such as liking or disliking; and behavioral attitude is related to what individuals have experienced, such as a tendency-towardaction (Reid, 2006; Reid \& Ali, 2020). Wan and Lee (2017) explored the relations among these components and conclude that students' behavioral attitude toward science is affected by their cognitive and affective attitude. Hence, citizens' behavioral attitude- a construct related to their science engagement experiences-might be predicted by their cognitive attitude and affective attitude. 


\section{Citizens' Cognitive and Affective Attitude Toward Science}

Emotional factors pertaining to science literacy include one's psychological state, which involves attention, effort, concentration, and affect triggered during engagementbut also include motivation, which can be characterized by reengagement over time (Renninger \& Hidi, 2017). Affective factors have played as significant determinants of wellbeing, optimism, and positive affect on life-long education participation (Martínez-Martí \& Ruch, 2017; Sari, 2019). Furthermore, Falk et al. (2007) posited that high level of individual learning interest is one of the significant predictors of public engagement in science. Along similar lines, researchers found that individual learning interest was a significant pathway leading to positive enjoyment of activity engagement (Schutte, 2014; Tse et al., 2021). Jones et al. (2017) explored factors contributing to hobbyists' life-long science learning and found that the hobbyists were motivated by their internal drive, learning resources, and socialize with those who have similar interests. Additional research findings also concluded that individual interest not only relates to long-term and advanced pursuit of knowledge, but also drives engagement with scientific activities (OECD, 2017; Renninger \& Hidi, 2017; Shin \& Kim, 2019). In view of the above literature, we hypothesized that citizens' interest in learning science might have an impact on related factors such as enjoyment of and self-efficacy in learning science.

Although science knowledge can affect peoples' engagement with science, cognitive attitude is crucial for citizens' science literacy (Takahashi \& Tandoc, 2016). In fact, research shows that perceived familiarity with science has a stronger effect on engagement than factual knowledge when citizens are confronted with social-scientific issues (Rose et al., 2019). In other words, compared to factual understanding, an individual's self-understanding of science might be a more powerful factor in the context of citizen engagement with science. Mujtaba et al. (2018) assessed the extent to which middle school students' self-understanding of science was related to their future engagement, and their findings showed that it has a small but relevant association. How or whether this relationship is sustained when students become adult citizens, however, remains unknown.

\section{Citizens' Behavioral Attitude Toward Science}

Learning enjoyment is another important construct in science learning. Learning enjoyment is the positive emotion people acquire from science activities, and this emotional response can motivate further engagement (Harlen, 2010). It has been shown to positively affect and carry further impact on students' learning engagement and re-engagement (Ainley \& Ainley, 2011; Schukajlow \& Rakoczy, 2016). For citizens, public scientific activities can provide them with an enjoyable context (e.g., a science festival) in which they may interact with latest scientific information (Jensen \& Buckley, 2014). Hence, citizens' experiences of learning enjoyment acquired in public science activities may be important for their reengagement.

Self-efficacy also is an attitudinal factor related to science engagement. Bandura (1994) states that perceived selfefficacy pertains to individuals' "beliefs in their capabilities to exercise control over their own functioning and over events that affect their lives" (p. 13). For students, self-efficacy is their confidence when engaging in academic tasks or activities (Lin et al., 2013a; Wang et al., 2020; Wang \& Tsai, 2019). Tsai et al. (2017) observed that the most important factor predicting adult scientific competencies is self-efficacy. Sleenhoff and Osseweijer (2016) explored citizens' self-efficacy when confronting a "bio-based" economy issue, and the research participants showed distinct ways of dealing with it, and their self-efficacy provided the citizens with a sense of being able to deal with the science-related problems. In citizens' daily lives, self-efficacy can attribute to their previous successful experiences and this form of behavioral attitude also may influence citizens' confidence or skills used to solve problems in their daily lives (Reid, 2006; Reid \& Ali, 2020).

\section{Background Factors Related to Science Attitude}

When focusing on attitude toward science, gender is a commonly studied factor. Mujtaba et al. (2018) assessed how science attitudes, beliefs, and context affect students, but their findings additionally show that gender has no correlation with future engagement. Other research shows no significant gender differences in either science interest or self-efficacy (Kelemen-Finan et al., 2018). However, inconsistent results appear in studies pertaining to adult citizens' attitudes. Takahashi and Tandoc (2016) explored factors related to how citizens learn science through the internet, newspapers, or television. Their results showed that males tend to have more factual knowledge and be more interested in science than females. Falk et al. (2018) explored how race, income, gender, and age relate to U.S. adults' science interest and cognitive predispositions, and their findings showed that age, Asian ethnicity, non-White ethnicity, and gender have no significant relationship with either outcome. In summary, then, research findings related to gender differences in science attitude remain inconsistent. Further, there is a paucity of research that examines how gender might moderate the effects of attitudinal variables on other outcomes.

In addition to gender, age is another characteristic that may relate to attitudes towards science. Kelemen-Finan et al. (2018), for example, examining the effects of a science project intervention on science interest and self-efficacy among students age 8-19 years of age, found that the youngest students 
(8-10 years) scored highest and differed significantly from both 13-14 year-old students and 15-19 year-old students. However, research assessing U.S. adult citizens (18 years and older) from three cities found that age was not significantly related to science attitude (Falk et al., 2018). Other research relating age to both attitude towards science, however, is limited, and few studies have examined whether age might moderate the effects of attitude on other outcomes such as science self-efficacy.

\section{Significance of this Study}

Although considerable research has emphasized the importance of scientific literacy including scientific knowledge, scientific attitudes and scientific skills (e.g., Bauer et al., 2007; Tsai et al., 2017), Falk et al. (2007) assert that many researchers focus on how well citizens understand science knowledge, rather than exploring citizens' affective attitude toward engaging in science related activities. Jensen and Buckley (2014) point out that if individuals have higher interest in science issues and public scientific activities, they may show greater passion for science learning. Tsai et al. (2017) indicated that the most important factor predicting citizen's scientific engagement is their self-understanding of science knowledge and science issues. However, limited attention has been focused on how citizen's scientific interest and self-understanding relate to their science learning enjoyment and scientific self-efficacy, although these affective factors may in fact have an impact on how citizens react and interact with science information or activities. Therefore, the aim of this study is to focus on four psychological constructs of scientific literacy (scientific interest, scientific self-understanding, science learning enjoyment, and scientific self-efficacy) to further examine the extent to which citizens' scientific interest and self-understanding of science issues predict their learning enjoyment and self-efficacy in science. Additionally, we assess the moderating effects of age and gender on these relationships. To these ends, there were three research questions posed in this study: 1) How do adult citizens' scientific interest and self-understanding relate to their learning enjoyment and self-efficacy in science? 2) Does gender moderate the effects of scientific interest and self-understanding on learning enjoyment or self-efficacy in science? 3) Does age moderate the effects of scientific interest and self-understanding on learning enjoyment or self-efficacy in science?

\section{Methods}

\section{Research Method and Framework}

This research employed a survey research design whereby data were collected through a questionnaire. Multiple regression analyses were used to examine the relationships among the psychological constructs. Drawing from the theoretical foundations discussed earlier, this research proposed the research framework shown in Fig. 1, which included three hypotheses $\left(\mathrm{H}_{1}-\mathrm{H}_{3}\right)$.

$\mathrm{H}_{1}$ : Adult citizens' scientific interest and self-understanding are related to their learning enjoyment and self-efficacy in science.

$\mathrm{H}_{2}$ : Gender moderates the effects of adult citizens' scientific interest and self-understanding on their learning enjoyment and self-efficacy in science.

$\mathrm{H}_{3}$ : Age moderates the effects of adult citizens' scientific interest and self-understanding on their learning enjoyment and self-efficacy in science.

\section{Participants and Settings}

The large-scale survey data were collected face-to-face between January and June 2018 in Taiwan. The participants were selected from 18- to 70-year-old Taiwan citizens using stratified sampling of 2018 households based on registration information. The sampling process of this study is based on eight indicators (population density; educational level; percentage of the population over the age of 65 ; percentage of the population between the age of 15 to 64; percentage of the population in the manufacturing industry; percentage of the population in the agricultural, forestry, fishery or animal husbandry industry; percentage of the population in professional and supervisory level industry; and five-year population growth rate). Three phases of probability proportional to size (PPS) sampling were conducted for each stratum based on "district—village—citizen" and samples were selected in accordance with population proportions (Table 1).

Before sampling, cluster analysis was used to divide all 358 districts in Taiwan into six strata according to their level of urbanization (Tsai \& Huang, 2018). The study then conducted three-phase "district—village—citizen" sampling: Systematic sampling was used to select 15 districts in phase 1; 30 villages within these districts were selected in phase 2; there were 2,004 citizens selected from the villages so that the proportion of participants from each stratum would match its proportion of the overall population in phase 3 . After excluding individuals who refused to participate, relocated or removed, the number of valid cases was 1,657 , including 811 women (48.9\%) and 846 men (51.1\%); 391 aged $18-29(23.6 \%), 385$ aged $30-39(23.3 \%), 369$ aged 40-49 (22.2\%), 341 aged 50-59 (20.6\%), and 171 aged 60-70 (10.3\%). Among the sample, 195 had a junior high school diploma (11.7\%), 528 had a high /vocational school diploma (31.9\%), 226 had a junior college diploma (13.6\%), 577 had a bachelor degree (34.8\%), 128 had a master degree 


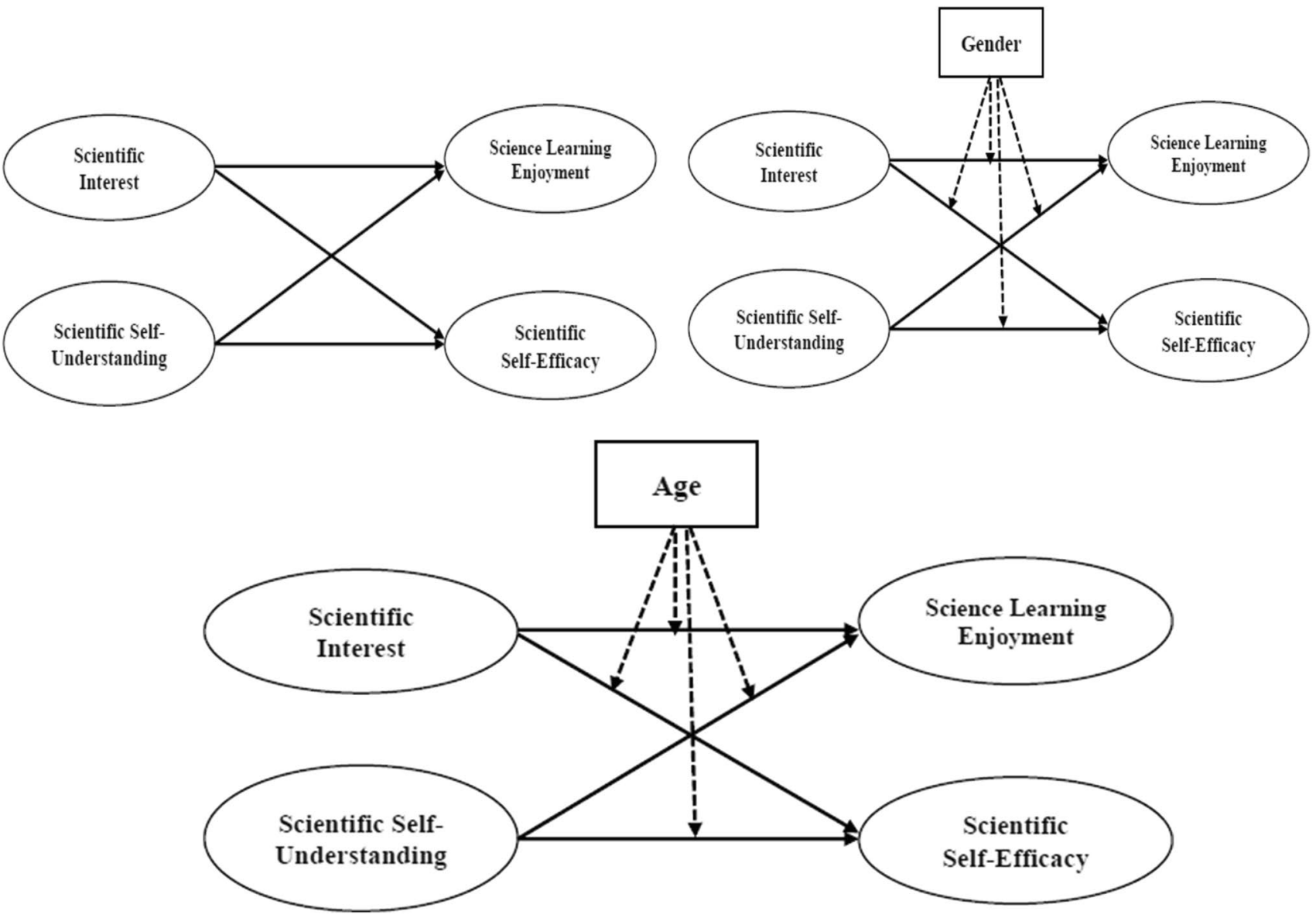

Fig. 1 Plots showing research frameworks of hypotheses $\left(\mathrm{H}_{1-} \mathrm{H}_{3}\right)$

Table 1 Sampling stratification for 2018 Taiwan Science Literacy Survey

\begin{tabular}{lllllll}
\hline Stratum & $\begin{array}{l}\text { Town- } \\
\text { ships/ } \\
\text { districts }\end{array}$ & Population (proportion) & $\begin{array}{l}\text { Phase 1 Sam- } \\
\text { pled districts }\end{array}$ & $\begin{array}{l}\text { Phase 2 Sam- } \\
\text { pled villages }\end{array}$ & $\begin{array}{l}\text { Phase 3 Sam- } \\
\text { pled citizens }\end{array}$ & $\begin{array}{l}\text { Com- } \\
\text { pleted } \\
\text { samples }\end{array}$ \\
\hline 1 & 17 & $1,838,459(0.116)$ & 3 & 6 & 234 & 167 \\
2 & 26 & $4,690,763(0.295)$ & 9 & 18 & 594 & 488 \\
3 & 44 & $3,673,132(0.231)$ & 7 & 14 & 462 & 375 \\
4 & 26 & $1,647,381(0.104)$ & 3 & 6 & 210 & 182 \\
5 & 102 & $2,645,387(0.167)$ & 5 & 10 & 330 & 296 \\
6 & 143 & $1,380,939(0.087)$ & 3 & 6 & 174 & 149 \\
Total & 358 & $15,876,061$ & 30 & 60 & 2,004 & 1,657 \\
\hline
\end{tabular}

(7.8\%), and 3 had a doctoral degree $(0.2 \%)$. Table 2 summarizes this information.

\section{Development and Validation of Instruments}

The instruments were adopted from the scale of 2018 "Taiwan Citizens Science and Technology Literacy Survey," which measured four primary constructs: scientific interest issues, scientific self-understanding, science learning enjoyment, and scientific self-efficacy.

\section{Scientific Interest Issues Scale (SIIS)}

The Scientific Interest Issues Scale (SIIS) was adapted from the National Science Board's (2016) Public Attitudes Toward Science and Technology Issues, and included seven items pertaining to seven scientific issues: new scientific 
Table 2 Frequency distribution for gender, age, and education

\begin{tabular}{llll}
\hline Characteristic & Value & Frequency & Percent \\
\hline Gender & Male & 846 & $51.1 \%$ \\
& Female & 811 & $48.9 \%$ \\
& Total & 1657 & $100.0 \%$ \\
Age & 18-29 years & 391 & $23.6 \%$ \\
& 30-39 years & 385 & $23.3 \%$ \\
& 40-49 years & 369 & $22.2 \%$ \\
Education & 50-59 years & 341 & $20.6 \%$ \\
& 60-70 years & 171 & $10.3 \%$ \\
& Total & 1657 & $100.0 \%$ \\
& Junior high school & 195 & $11.7 \%$ \\
& High /vocational school & 528 & $31.9 \%$ \\
& Junior College & 226 & $13.6 \%$ \\
& Bachelor degree & 577 & $34.8 \%$ \\
& Master degree & 128 & $7.8 \%$ \\
& Doctoral degree & 3 & $0.2 \%$ \\
& Total & 1657 & $100.0 \%$ \\
\hline
\end{tabular}

Note. Frequencies computed using the provided sampling weights.

discovery, using of new technology, new medical discovery, space exploration, environmental protection, renewable energy, and air pollution. Participants were asked to rate each of the seven Likert-type items using 4-point response options $(1=$ strongly uninterested, $2=$ uninterested, $3=$ inter ested, $4=$ strongly interested ), and a composite score was computed as the sum of the seven item scores, and where a higher composite score indicated greater interest in scientific issues. The observed composite SIIS scores ranged from 7 to 28. In addition, a confirmatory factor analysis (CFA) was conducted to evaluate how well a unidimensional model fit the data from Taiwanese citizens. Using guidelines from $\mathrm{Hu}$ and Bentler (1999), the results from this CFA established that the unidimensional model for the seven items provided adequate fit to the data $\left[\chi^{2}(14)=37.06, p<0.001\right.$; $\mathrm{GFI}=0.91 ; \mathrm{CFI}=0.90 ; \mathrm{SRMR}=0.06$; $\mathrm{RMSEA}=0.06]$, with factor loadings ranging in value from 0.55 to 0.76 $(p<0.001)$ and correlation coefficients ranging in value from 0.50 to $0.70(p<0.001)$. The reliability results indicated that the AVE value was 0.48 , meeting the criterion suggested by Fornell and Larcker (1981). The composite reliability (CR) was 0.87 , meeting the criterion provided by Bogozzi and Yi (1988).

\section{Scientific Self-Understanding Issues Scale (SSUIS)}

The Scientific Self-Understanding Issues Scale (SSUIS) was based on the National Science Board's (2016) Public Understanding of Science and Technology Issues, and included seven items pertaining to seven scientific issues: new scientific discovery, using of new technology, new medical discovery, space exploration, environmental protection, renewable energy, and air pollution. All participants were asked to rate each of the Likert-type items using 4-point response options $(1=$ strongly uninformed, $2=$ uninformed, $3=$ informed, $4=$ strongly informed ). A composite score was computed as the sum of the item scores, where a higher total score indicated greater self-understanding of scientific issues. The total SSUIS scores ranged from 7 to 28 . In addition, results from CFA showed that a unidimensional model provided adequate fit to the data $\left[\chi^{2}(14)=44.46, p<0.001\right.$; $\mathrm{GFI}=0.90 ; \mathrm{CFI}=0.89 ; \mathrm{SRMR}=0.06 ; \mathrm{RMSEA}=0.06]$. Factor loadings ranged in value from 0.51 to $0.74(p<0.001)$ and correlation coefficients ranging in value from 0.47 to $0.65(p<0.001)$. The AVE value was 0.45 , and the composite reliability $(\mathrm{CR})$ was 0.85 , meeting the criteria provided by Fornell and Larcker (1981) and Bogozzi and Yi (1988), respectively.

\section{Science Learning Enjoyment Scale (SLES)}

The Science Learning Enjoyment Scale (SLES) was derived from PISA questionnaires designed to assess enjoyment in science learning (OECD 2017), and included five items: "Generally, I have fun from studying science," "I like to read about science topics," "I will be very happy when studying topics related to science," "I will be happy when I get a new science-related knowledge," and "I am interested in studying science." All participants were asked to rate each item using a 4-point Likert response options $(1=$ strongly disagree, $2=$ disagree, $3=$ agree, $4=$ strongly agree). Composite scores were computed as the sum of the item scores, where a higher total score indicated greater enjoyment of science learning. The observed composite SLES scores ranged in value from 5 to 20 . In addition, CFA conducted to evaluate how well a unidimensional structure fit the data from Taiwanese citizens provided good fit to the data $\left[\chi^{2}(5)=3.39, p<0.001 ; \mathrm{GFI}=0.99 ; \mathrm{CFI}=0.99\right.$; SRMR $=0.01$; RMSEA $=0.04]$, with factor loadings ranging in value from 0.74 to $0.87(p<0.001)$ and correlation coefficients ranging in value from 0.70 to $0.82(p<0.001)$. The AVE value was 0.67 and the composite reliability (CR) was 0.91 , suggesting good reliability based on the criteria provided by Fornell and Larcker (1981) and Bogozzi and Yi (1988), respectively.

\section{Scientific Self-Efficacy Scale (SSES)}

The Scientific Self-Efficacy Scale (SSES) was derived from PISA questionnaires designed to measure individuals' selfconfidence in future scientific topics. This questionnaire was developed for young adults and also validated for an adult cohort in a prior study (Tsai et al., 2017). The SSES consisted of 8 items-for example, "How easy do you think 
it would be for you to perform the following tasks on your own? Finding out the scientific questions from the media's health issues report." All participants were asked to respond to each item using 4-point Likert-type response options $(1=I$ couldn't do this, $2=I$ would struggle to do this on my own, $3=\mathrm{I}$ could do this with a bit of effort, $4=I$ could do this easily). A composite score was computed as the sum of the item scores, where a higher composite score indicated higher self-efficacy in scientific topics. The observed composite SSES scores ranged from 8 to 32, with good evidence of internal consistency (alpha $=0.87$ ). Results from a CFA indicated that the unidimensional model provided good fit to the data $\left[\chi^{2}(20)=11.78, p<0.001\right.$; GFI $=0.96$; $\mathrm{CFI}=0.96$; $\mathrm{SRMR}=0.04$; RMSEA $=0.08]$, with factor loadings ranging in value from 0.53 to $0.76,(p<0.001)$ and correlation coefficients ranging in value from 0.49 to $0.70(p<0.001)$. The reliability results indicated that the AVE values was 0.45, meeting Fornell and Larcker's (1981) criterion. The composite reliability (CR) was 0.87 , meeting Bogozzi and Yi’s (1988) criterion.

\section{Data Analyses}

We carried out multiple regression analyses to examine the predictive effects of citizens' scientific interest and selfunderstanding on their science learning enjoyment and scientific self-efficacy, as well as assessing the moderating effects of gender and age on citizens' science learning enjoyment and scientific self-efficacy. All statistics and regression models were computed using the provided sampling weights.

\section{Results}

\section{Citizens' Scientific Interest and Self-Understanding Relate to their Learning Enjoyment and Self-Efficacy in Science}

The study used multiple regression to assess the effects of citizens' scientific interest, self-understanding, gender, age, and education on their science learning enjoyment and scientific self-efficacy. For each analysis, the regression assumptions of linearity, homoscedasticity, and normality of residuals were assessed and met. A model fitted using this set of predictors explained $21.6 \%$ of the total variability in science learning enjoyment and $6.3 \%$ of the variability in scientific self-efficacy. As can be seen in Table 3, three predictors (interest, self-understanding, and gender) each significantly predicted these outcomes. Specifically, higher scientific interest and self-understanding were associated with both higher science learning enjoyment $(\beta=0.315, p<0.001$ and $\beta=0.190, p<0.001)$ and higher scientific self-efficacy ( $\beta=0.071, p<0.001$ and $\beta=0.154, p<0.001$ ), while male citizens had higher science learning enjoyment $(\beta=0.097$, $p<0.001)$ and scientific self-efficacy $(\beta=0.072, p<0.01)$ than female citizens. Additionally, age positively and significantly predicted science learning enjoyment $(\beta=0.076$, $p<0.01$ ); while education positively and significantly predicted scientific self-efficacy $(\beta=0.097, p<0.001)$. Examination of Pratt (1987) indices as indicators of the relative importance of each of the predictors in the model (Table 3) showed that scientific interest was the most important predictor of science learning enjoyment, and scientific selfunderstanding was the most important predictor of scientific self-efficacy.

\section{The Moderating Effect of Gender on Scientific Interest and Self-Understanding on Learning Enjoyment or Self-Efficacy in Science}

We next fitted regression models to examine how the effects of scientific interest and self-understanding on each of the two outcomes (science learning enjoyment and scientific self-efficacy) were moderated by gender. Regression models containing these moderation effects showed that $21.8 \%$ of the variability in science learning enjoyment and $6.3 \%$ of the variability in scientific self-efficacy was explained by the full set of predictors (main effects and interaction effects). These regressions revealed that gender did not significantly moderate the effects of either scientific interest or self-understanding on science learning enjoyment or scientific self-efficacy. That is, the observed positive effects of scientific interest and self-understanding on these outcomes did not vary by gender (Table 4).
Table 3 Summary of regression analyses for effect of citizens' scientific interest and self-understanding on their science learning enjoyment and scientific self-efficacy $(N=1657)$

\begin{tabular}{|c|c|c|c|c|c|c|c|c|c|c|}
\hline \multirow[b]{2}{*}{ Predictor } & \multicolumn{5}{|c|}{ Science Learning Enjoyment $\left(R^{2}=0.216\right)$} & \multicolumn{5}{|c|}{ Scientific Self-efficacy $\left(R^{2}=0.063\right)$} \\
\hline & $b$ & $S E(b)$ & $\beta$ & $t$ & Pratt & $b$ & $S E(b)$ & $\beta$ & $t$ & Pratt \\
\hline interest & 0.245 & 0.020 & 0.315 & $12.555 * * *$ & 0.600 & 0.084 & 0.033 & 0.071 & $2.583 * * *$ & 0.180 \\
\hline self-understanding & 0.151 & 0.020 & 0.190 & $7.580 * * *$ & 0.310 & 0.187 & 0.033 & 0.154 & $5.642 * * *$ & 0.510 \\
\hline gender (male) & 0.645 & 0.147 & 0.097 & $4.395 * * *$ & 0.060 & 0.738 & 0.245 & 0.072 & $3.013 * *$ & 0.110 \\
\hline age & 0.194 & 0.062 & 0.076 & $3.107 * *$ & 0.030 & 0.050 & 0.104 & 0.013 & 0.476 & 0.010 \\
\hline education & -0.002 & 0.068 & -0.001 & -0.023 & 0.000 & 0.409 & 0.114 & 0.097 & $3.587 * * *$ & 0.190 \\
\hline
\end{tabular}

Note. ${ }^{* *} p<0.01, * * * p<0.001$. 


\section{The Moderating Effect of Age on Scientific Interest and Self-Understanding on Learning Enjoyment or Self-Efficacy in Science}

Finally, we constructed regression models to examine how the effects of scientific interest and self-understanding on each of the two outcomes (science learning enjoyment and scientific self-efficacy) were moderated by age. The results indicated that $23.7 \%$ of the total variability in $s c i$ ence learning enjoyment and $7.6 \%$ of the variability in scientific self-efficacy was explained by the full set of predictors. As shown in Table 5, these regressions showed statistically significant moderating effects of age on the relationship between citizens' scientific interest and both science learning enjoyment $(\beta=-0.151, p<0.001)$ and scientific self-efficacy $(\beta=-0.054, p<0.05)$ as well as a significant moderating effect on the relationship between citizens' scientific self-understanding and scientific selfefficacy $(\beta=-0.081, p<0.01)$. The plot displayed in Fig. 2 illustrate these moderation effects, and show that the predictive effect of both 1) scientific interest on science learning enjoyment and scientific self-efficacy 2) scientific selfunderstanding on scientific self-efficacy was stronger for younger citizens than for older citizens.

\section{Discussion and educational implications}

This paper examines how citizens' scientific interest and self-understanding relate to their learning enjoyment and self-efficacy in science. The major findings of this study strengthen and extend our understanding of the effects of affective factors on citizen science learning outcomes. Three findings from this investigation are noteworthy and add value to current science education literature. The first finding of note is the significant predictive effects of scientific interest, self-understanding, and gender on citizens' science learning enjoyment and scientific self-efficacy. Harlen (2010) points out that when people have more interest in science activities, this may influence their enjoyment in science learning. OECD (2017) also asserts that one's understanding of scientific importance is related to their engagement and life-long learning of science. The OECD (2017) study suggests that, if individuals have increased interest in scientific issues such as a new scientific discovery, they may be more attentive to scientific news and information, as well as participate in scientific activities that may boost their learning enjoyment in science. Furthermore, when citizens have greater opportunity to acquire scientific knowledge and understand scientific issues and information, they may have
Table 4 Summary of regression analyses for moderating effect of gender on the relationship between citizens' scientific interest and self-understanding to their science learning enjoyment and scientific selfefficacy $(N=1657)$

\begin{tabular}{llllllllll}
\hline & \multicolumn{3}{l}{$\begin{array}{l}\text { Science Learning Enjoyment } \\
\left(R^{2}=0.218\right)\end{array}$} & \multicolumn{7}{l}{$\begin{array}{l}\text { Scientific Self-efficacy } \\
\left(R^{2}=0.063\right)\end{array}$} \\
\hline Predictor & $b$ & $S E(b)$ & $\beta$ & $t$ & $b$ & $S E(b)$ & $\beta$ & $t$ \\
Interest & 0.219 & 0.031 & 0.281 & $7.119^{* * * *}$ & 0.110 & 0.051 & 0.092 & $2.133^{*}$ \\
self-understanding & 0.124 & 0.029 & 0.156 & $4.221^{* * *}$ & 0.211 & 0.049 & 0.174 & $4.302^{* * *}$ \\
gender (male) & 0.655 & 0.147 & 0.098 & $4.457^{* * *}$ & 0.730 & 0.245 & 0.072 & $2.977^{* *}$ \\
Age & 0.195 & 0.062 & 0.076 & $3.121^{* *}$ & 0.049 & 0.104 & 0.013 & 0.468 \\
Education & 0.001 & 0.068 & 0.000 & 0.014 & 0.407 & 0.114 & 0.097 & $3.564^{* * *}$ \\
interest $\times$ gender (male) & 0.038 & 0.040 & 0.039 & 0.950 & -0.036 & 0.066 & -0.024 & -0.549 \\
self-understanding $\times$ gender (male) $)$ & 0.045 & 0.040 & 0.044 & 1.140 & -0.041 & 0.067 & -0.026 & -0.609 \\
\hline
\end{tabular}

Note. $* p<0.05, * * p<0.01, * * * p<0.001$.

\begin{tabular}{|c|c|c|c|c|c|c|c|c|}
\hline \multirow[b]{2}{*}{ Predictor } & \multicolumn{4}{|c|}{$\begin{array}{l}\text { Science Learning Enjoyment } \\
\left(R^{2}=0.237\right)\end{array}$} & \multicolumn{4}{|c|}{ Scientific Self-efficacy $\left(R^{2}=0.076\right)$} \\
\hline & $b$ & $S E(b)$ & $\beta$ & $t$ & $b$ & $S E(b)$ & $\beta$ & $t$ \\
\hline interest & 0.243 & 0.019 & 0.312 & $12.495 * * *$ & 0.095 & 0.033 & 0.080 & $2.906 * *$ \\
\hline self-understanding & 0.156 & 0.020 & 0.196 & $7.721 * * *$ & 0.166 & 0.034 & 0.137 & $4.889 * * *$ \\
\hline gender (male) & 0.625 & 0.145 & 0.093 & $4.311 * * *$ & 0.706 & 0.243 & 0.069 & $2.899 * *$ \\
\hline age & 0.187 & 0.062 & 0.073 & $3.030 * *$ & 0.062 & 0.104 & 0.016 & 0.598 \\
\hline education & -0.017 & 0.068 & -0.006 & -0.249 & 0.407 & 0.114 & 0.097 & $3.589 * * *$ \\
\hline interest $\times$ age & -0.091 & 0.015 & -0.151 & $-6.261 * * *$ & -0.050 & 0.024 & -0.054 & $-2.042 *$ \\
\hline self-understanding $\times$ age & 0.010 & 0.014 & 0.016 & 0.658 & -0.073 & 0.024 & -0.081 & $-2.999 * *$ \\
\hline
\end{tabular}

Note. $* p<0.05, * * p<0.01, * * * p<0.001$.
Table 5 Summary of regression analyses for moderating effect of age on the relationship between citizens' scientific interest and self-understanding to their science learning enjoyment and scientific selfefficacy $(N=1657)$ 

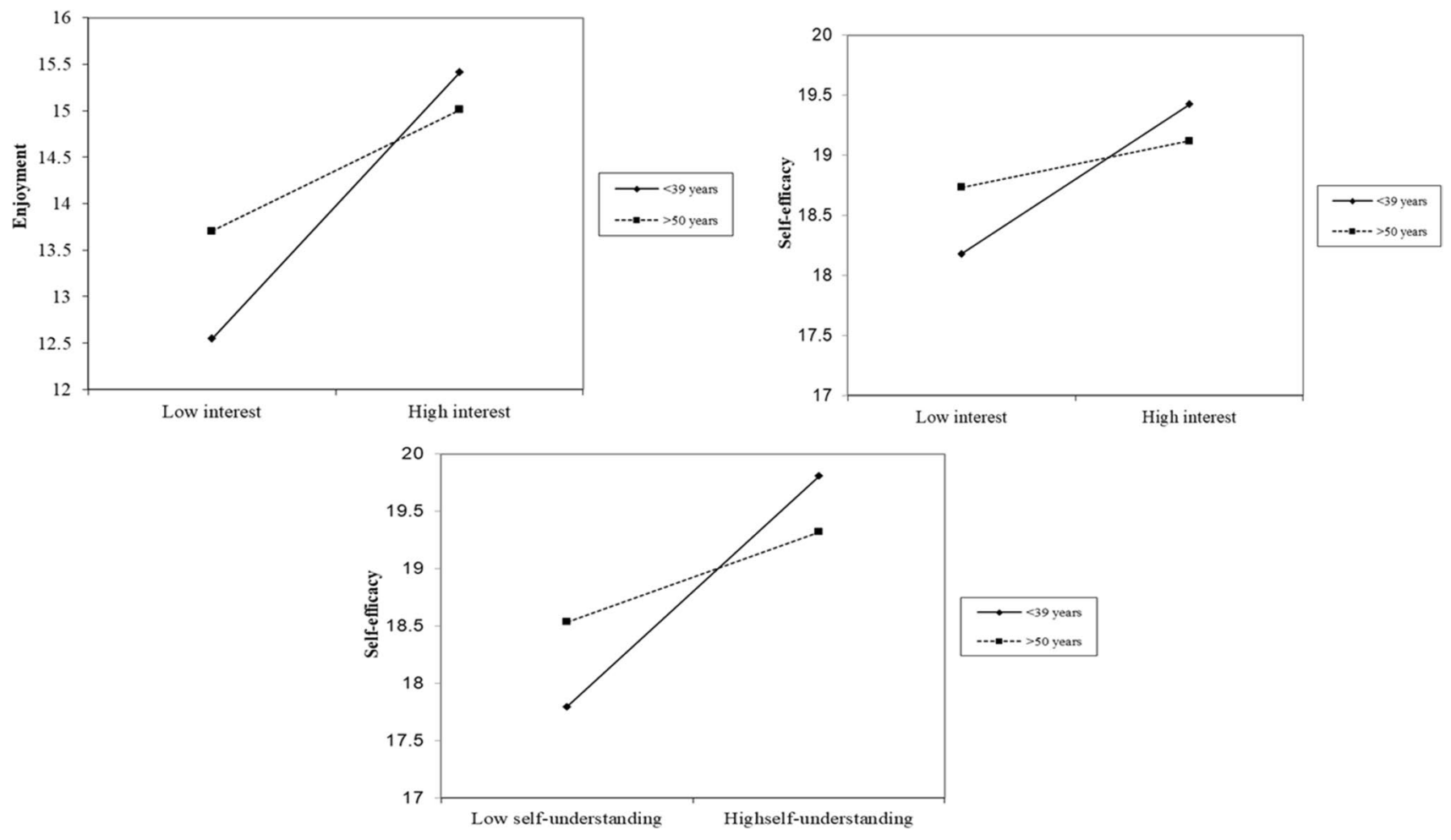

Fig. 2 Plots showing moderating effects of age on the relationship between 1) citizens' scientific interest and scientific enjoyment, 2) scientific interest and scientific self-efficacy, and 3) scientific self-understanding and scientific self-efficacy

more self-confidence to solve problems and complete tasks by using scientific thinking strategies.

The second finding of note is the effect of gender on citizens' science learning enjoyment and scientific self-efficacy. A phenomenon observed over several decades in Taiwanese and Chinese societies is that, in accordance with societal expectations, men tend to prefer science-related education while women tend to prefer socially-related education (Tsai et al., 2017; Wang, 2012). This may be one reason why parallel differences are observed between males' and females' attitudes towards science learning, scientific selfefficacy, and even career choices. However, due to the rapid development of science and technology and the global promotion of gender mainstreaming, more women have been entering science and technology fields and the scientific community more generally (Wang, 2012). In our study, we found that gender had no significant moderating effect on the relationship between either citizens' scientific interest or self-understanding and their science learning enjoyment or scientific self-efficacy. Therefore, we recommended that educational instructors can arrange educational activities in a gender-equitable manner that is equally suitable for male and female students, and discuss scientific issues from multiple perspectives. It also is suggested that educational policies that implement gender mainstreaming be considered. These can help to ensure that men and women receive both equal treatments in society and public affairs and equal access to social resources. In this way, both men and women may enjoy equal opportunity to learn informal science in a way that can build their scientific interest and self-understanding pertaining to scientific issues, which then may play an important role to enhance their science learning enjoyment and scientific self-efficacy.

The third finding of note in this study is the moderating effect of age on citizens' science learning enjoyment and scientific self-efficacy. Previous studies have found no significant effect of age on citizens' science learning attitude (Falk et al., 2018). However, the current study sheds light on both the main effects of age on science learning enjoyment, as well as the moderating role of age on the relationship between citizens' science learning enjoyment and their scientific self-efficacy. Specifically, age was positively associated with learning enjoyment, and the predictive effects of interest and understanding were stronger among younger citizens. Maltese and Tai (2011) found that scientific interest during early adolescence is a key variable in predicting involvement in further science education and careers. Kelemen-Finan et al. (2018) also demonstrated that many of the leading theories of academic and career pathways position self-understanding as a central variable driving youths' and young adults' motivations and beliefs to complete scientific tasks. Their results showed that when younger citizens 
had more interest in scientific issues, they spend more time engaging in scientific activities, reading more scientific books and news, and searching for more scientific information-all activities that could increase their enjoyment in scientific learning. When these younger adults had more opportunities to understand scientific issues that may help them to establish higher scientific-related literacy, they had much higher self-confidence to solve the problems with scientific strategies. These findings serve as a reminder to policy-makers that more informal learning environments for older adults can help them to engage in scientific inquiry and explore new scientific discoveries to raise their interest in, and self-understanding of, scientific issues, which then can enhance their learning enjoyment and scientific self-efficacy.

\section{Limitations}

Although the current study provides insight into factors that contribute to adult learning enjoyment and self-efficacy, like all studies it is constrained by particular limitations and should not be viewed as definitive. One clear limitation involves the validity of using self-report data for both the outcomes and predictors. Although the use of self-report data is a common approach in research, it can be subject to external bias caused by social desirability and approval (Althubaiti, 2016). Similar challenges arise due to the use of retrospective data as a surrogate for actual experiences, as such data can either underestimate or overestimate the true effect or association (Mueller \& Gaus, 2015). Another limitation involves the generalizability of findings. Although data were collected solely in Taiwan-and we are quite confident that findings reliably reflect these areas of Taiwan, we cannot hold equal confidence that the findings fully generalize to other parts of Taiwan, let alone other parts of the world. Whether fully generalizable or not, these findings provide a useful and reasonable baseline for understanding how Taiwanese citizens' scientific interest and self-understanding relate to their learning enjoyment and self-efficacy in science. Future research efforts might extend this exploration by examining longitudinal data to assess how learning enjoyment and self-efficacy in science are predicted by both the quantity and quality of learning experiences over the course of an individual's lifetime.

\section{Conclusion and Suggestions}

The study explored how Taiwanese citizens' scientific interest and self-understanding were related to their learning enjoyment and self-efficacy in science. Results presented here suggest that Taiwanese citizens' interest in and self-understanding of scientific issues experiences were particularly important factors to predict their science learning enjoyment and scientific self-efficacy. This is supported by extant research, where citizens having higher interest in scientific issues are more likely to engage in scientific activities such as watching scientific television, reading scientific books and magazines, visiting science museums, and show enhanced enjoyment of science learning (Vilia \& Candeias, 2020; Wan \& Lee, 2017). It would appear, then, that when Taiwanese citizens engage in scientific experiences throughout their lives and, to the degree these experiences are positive, this should support higher self-understanding of scientific issues. Thus, it appears that a sound scientific education policy would strive to support-not a single type of science resource-but, rather, multiple sources to improve citizens' scientific literacy, and by extension, their science learning enjoyment and scientific self-efficacy.

Results in this study indicated that male gender had a significant positive effect on citizens' learning enjoyment and scientific self-efficacy. These results are consistent with a number of previous studies showing that male students have higher interest in scientific learning and greater opportunity to choose scientific careers than female students (e.g., Ainley \& Ainley, 2011; Schukajlow \& Rakoczy, 2016; Takahashi \& Tandoc, 2016). However, the present study found no gender differences in how either interest or understanding was related to the outcomes of learning enjoyment or scientific self-efficacy. This, combined with the fact that the most important contributors to adult scientific interest and self-understanding were non-school experiences, raises important policy issues (Jones et al., 2017). Given that there is a world-wide concern for increasing the long-term enjoyment of, and engagement in science by all citizens, these and other recent studies suggest that the goal of enhancing science equity might best be achieved through increased social support for both male and female citizens' scientific free-choice learning.

The results of this study indicated significant moderating effects of age on the relationship between both scientific interest and self-understanding and either or both of the outcomes (science learning enjoyment and scientific selfefficacy). The positive predictive power of scientific interest on science learning enjoyment and on scientific self-efficacy was stronger in younger citizens than in older citizens. Similarly, the positive association of self-understanding with scientific self-efficacy also was stronger among younger citizens. The following explanations are worthwhile to consider: First, although older persons may tend to enjoy learning science, their scientific interest may be less strongly associated with enjoyment of science compared to younger persons due to a potential lack of interesting scientific learning environment stimuli in their lives. To promote older citizens' enjoyment of science learning, they should be encouraged to take more time to engage in science-related pasttimes (e.g., visits 
to natural science museums, science and technology museums, planetariums, aquariums, zoos, botanical gardens, and national parks. When they have more opportunities to participate in scientific learning environments, this may boost their interest in scientific issues and enhance their enjoyment in science learning. Secondly, older citizens may have lower scientific self-efficacy than younger citizens due to their long period of removal from formal school education. Thus, we suggest that government and universities should offer more scientific-related extension education courses, speeches, workshops, and informal educational environments for those older citizens to increase their interest in science learning and to build their self-efficacy in science learning. Finally, older people likely have fewer opportunities to experience and engage with interesting scientific and technological activities due to their usual busy lives. In this regard, we consider that family-oriented (including younger and older family members) scientific co-learning activities, such as watching TV shows related to science, collaboratively searching for online information about science, and reading scientific magazines or newspaper articles together, is a good way to help these older citizens to improve their self-understanding of scientific issues, which then may influence their self-confidence and self-efficacy in science learning. To sum up, we suggest that governments, educational agencies, and coordinating bodies should pay more attention to facilitating life-oriented, contextualized, free-choice, and scientifically-oriented learning environments for older adults. Creating a citizenry who persistently are interested in science requires building all components of the scientific learning infrastructure and focusing on all citizens.

Data Availability Citizen performance data files are not publicly available due to confidentiality concerns.

\section{Declarations}

Conflict of Interest On behalf of all authors, the corresponding author states that there is no conflict of interest. The work described has not been published previously. This manuscript was approved by all authors. Informed consent was obtained from all individual participants included in the study. The work was reviewed by the institutional review board (IRB) developed by the Academia Sinica in Taiwan.

\section{References}

Ainley, M., \& Ainley, J. (2011). Student engagement with science in early adolescence: The contribution of enjoyment to students' continuing interest in learning about science. Contemporary Educational Psychology, 36(1), 4-12. https://doi.org/10.1016/j. cedpsych.2010.08.001

Althubaiti, A. (2016). Information bias in health research: Definition, pitfalls, and adjustment methods. Journal of Multidisciplinary Healthcare, 9, 211-217. https://doi.org/10.2147/JMDH.S104807
Ballantyne, R., \& Packer, J. (2009). Introducing a fifth pedagogy: Experience-based strategies for facilitating learning in natural environments. Environmental Education Research, 15(2), 243262. https://doi.org/10.1080/13504620802711282

Bandura, A. (1986). Social foundations of thought and action. New York, NY: Prentice-Hall.

Bandura, A. (1994). Self-efficacy. In V. S. Ramachaudran (Ed.), Encyclopedia of human behavior (Vol. 4, pp. 71-81). New York: Academic Press.

Bandura, A. (1997). Self-efficacy: The exercise of control. New York, NY: W. H. Freeman.

Bauer, M. W., Allum, N., \& Miller, S. (2007). What can we learn from 25 years of PUS survey research? Liberating and expanding the agenda. Public Understanding of Science, 16(1), 79-95. https:// doi.org/10.1177/0963662506071287

Bell, P., Lewenstein, B., Shouse, A., \& Feder, M. (2009). Learning science in informal environments: People, places, and pursuits. Washington DC: The National Academies Press.

Bogozzi, R. P., \& Yi, Y. (1988). On the evaluation of structural equation models. Academic of Marketing Science, 16, 74-94. https:// doi.org/10.1007/BF02723327

Bucchi, M., \& Saracino, B. (2016). "Visual Science Literacy" images and public understanding of science in the digital age. Science Communication, 38(6), 812-819. https://doi.org/10.1177/10755 47016677833

Chin, C. C., Yang, W. C., \& Tuan, H. L. (2016). Argumentation in a socioscientific context and its influence on fundamental and derived science literacies. International Journal of Science and Mathematics Education, 14(4), 603-617. https://doi.org/10.1007/ s10763-014-9606-1

Corin, E. N., Jones, M. G., Andre, T., \& Childers, G. M. (2018). Characteristics of lifelong science learners: An investigation of STEM hobbyists. International Journal of Science Education, Part B, 8(1), 53-75. https://doi.org/10.1080/21548455.2017.1387313

Falk, J. H., Storksdieck, M., \& Dierking, L. D. (2007). Investigating public science interest and understanding: Evidence for the importance of free-choice learning. Public Understanding of Science, 16(4), 455-469. https://doi.org/10.1177/0963662506064240

Falk, J. H., Pattison, S., Meier, D., Bibas, D., \& Livingston, K. (2018). The contribution of science-rich resources to public science interest. Journal of Research in Science Teaching, 55(3), 422-445. https://doi.org/10.1002/tea.21425

Fornell, C., \& Larcker, D. F. (1981). Evaluating structural equation models with unobservable variables and measurement error. Journal of Marketing Research, 18(1), 39-50. https://doi.org/10.1177/ 002224378101800104

Hardin, E., \& Longhurst, M. O. (2016). Understanding the gender gap: Social cognitive changes during an introductory stem course. Journal of Counseling Psychology, 63(2), 233-239. https://doi. org/10.1037/cou0000119

Harlen, W. (Ed.). (2010). Principles and big ideas of science education. Hatfield, Herts: Association for Science Education College Lane.

Hu, L.-T., \& Bentler, P. M. (1999). Cutoff criteria for fit indexes in covariance structure analysis: Conventional criteria versus new alternatives. Structural Equation Modeling: A Multidisciplinary Journal, 6(1), 1-55. https://doi.org/10.1080/10705519909540118

Jensen, E., \& Buckley, N. (2014). Why people attend science festivals: Interests, motivations and self-reported benefits of public engagement with research. Public Understanding of Science, 23(5), 557573. https://doi.org/10.1177/0963662512458624

Jones, M. G., Corin, E. N., Andre, T., Childers, G. M., \& Stevens, V. (2017). Factors contributing to lifelong science learning: Amateur astronomers and birders. Journal of Research in Science Teaching, 54(3), 412-433. https://doi.org/10.1002/tea.21371

Kelemen-Finan, J., Scheuch, M., \& Winter, S. (2018). Contributions from citizen science to science education: An examination of 
a biodiversity citizen science project with schools in Central Europe. International Journal of Science Education, 40(17), 2078-2098. https://doi.org/10.1080/09500693.2018.1520405

Lin, T.-J., Tan, A. L., \& Tsai, C.-C. (2013a). A cross-cultural comparison of Singaporean and Taiwanese eighth graders' science learning self-efficacy from a multi-dimensional perspective. International Journal of Science Education, 35(7), 1083-1109. https:// doi.org/10.1080/09500693.2013.776193

Lin, H., Lawrenz, F., Lin, S., \& Hong, Z. R. (2013b). Relationships among affective factors and preferred engagement in sciencerelated activities. Public Understanding of Science, 22(8), 941954. https://doi.org/10.1177/0963662511429412

Maltese, A. V., \& Tai, R. H. (2011). Pipeline persistence: Examining the association of educational experiences with earned degrees in STEM among U.S. students. Science Education, 95(5), 877-907. https://doi.org/10.1002/sce.20441

Martínez-Martí, M. L., \& Ruch, W. (2017). Character strengths predict resilience over and above positive affect, self-efficacy, optimism, social support, self-esteem, and life satisfaction. The Journal of Positive Psychology, 12(2), 110-119. https://doi.org/10.1080/ 17439760.2016.1163403

Meyer, G. (2016). In science communication, why does the idea of a public deficit always return? Public Understanding of Science, 25(4), 433-446. https://doi.org/10.1177/0963662516629747

Mueller, C. E., \& Gaus, H. (2015). Assessing the performance of the "counterfactual as self-estimated by program participants": Results from a randomized controlled trial. American Journal of Evaluation, 36(1), 7-24. https://doi.org/10.1177/1098214014 538487

Mujtaba, T., Sheldrake, R., Reiss, M. J., \& Simon, S. (2018). Students' science attitudes, beliefs, and context: Associations with science and chemistry aspirations. International Journal of Science Education, 40(6), 644-667. https://doi.org/10.1080/09500693.2018. 1433896

National Science Board. (2016). Science and engineering indicators 2016. Retrieved from https://www.nsf.gov/nsb/publications/2016/ nsb20161.pdf

Oh, J., Sudarshan, S., Jin, E., Nah, S., \& Yu, N. (2020). How 360-degree video influences content perceptions and environmental behavior: The moderating effect of environmental self-efficacy. Science Communication, 42(4), 423-453. https://doi.org/10.1177/ 1075547020932174

Organisation for Economic Co-operation Development (2017). PISA 2015 assessment and analytical framework: Science, reading, mathematic, financial literacy and collaborative problem solving. Paris, France: Author.

Porras-Hernández, L. H., \& Salinas-Amescua, B. (2012). Nonparticipation in adult education: From self-perceptions to alternative explanations. Adult Education Quarterly, 62(4), 311-331. https:// doi.org/10.1177/0741713611406980

Pratt, J. W. (1987). Dividing the indivisible: Using simple symmetry to partition variance explained. In T. Pukkila \& S. Puntanen (Eds.), Proceedings of the Second International Conference in Statistics (pp. 245-260). Tampere, Finland: University of Tampere.

Reid, N. (2006). Thoughts on attitude measurement. Research in Science \& Technological Education, 24(1), 3-27. https://doi.org/10. 1080/02635140500485332

Reid, N., \& Ali, A. A. (2020). Beliefs and attitudes: Why do attitudes matter? In Making Sense of Learning (pp. 253-279). Switzerland, AG: Springer.

Renninger, K., \& Hidi, S. (2017). The power of interest for motivation and engagement. New York: Routledge.

Rose, K. M., Howell, E. L., Su, L. Y. F., Xenos, M. A., Brossard, D., \& Scheufele, D. A. (2019). Distinguishing scientific knowledge: The impact of different measures of knowledge on genetically modified food attitudes. Public Understanding of Science, 28(4), 449-467. https://doi.org/10.1177/0963662518824837

Rutjens, B. T., van der Linden, S., \& van der Lee, R. (2021). Science skepticism in times of COVID-19. Group Processes \& Intergroup Relations, 24(2), 276-283. https://doi.org/10.1177/1368430220 981415

Sari, S. V. (2019). Attaining career decision self-efficacy in life: Roles of the meaning in life and the life satisfaction. Current Psychology, 38(5), 1245-1252. https://doi.org/10.1007/s12144-017-9672-y

Schukajlow, S., \& Rakoczy, K. (2016). The power of emotions: Can enjoyment and boredom explain the impact of individual preconditions and teaching methods on interest and performance in mathematics? Learning and Instruction, 44, 117-127. https:// doi.org/10.1016/j.learninstruc.2016.05.001

Schutte, N. S. (2014). The broaden and build process: Positive affect, ratio of positive to negative affect and general self-efficacy. The Journal of Positive Psychology, 9(1), 66-74. https://doi.org/10. 1080/17439760.2013.841280

Shin, D. D., \& Kim, S.-I. (2019). Homo curious: Curious or interested? Educational Psychology Review, 31(4), 853-874. https://doi.org/ 10.1007/s10648-019-09497-x

Simis, M. J., Madden, H., Cacciatore, M. A., \& Yeo, S. K. (2016). The lure of rationality: Why does the deficit model persist in science communication? Public Understanding of Science, 25(4), 400-414. https://doi.org/10.1016/10.1177/0963662516629749

Sleenhoff, S., \& Osseweijer, P. (2016). How people feel their engagement can have efficacy for a bio-based society. Public Understanding of Science, 25(6), 719-736. https://doi.org/10.1177/ 0963662514566749

Snow, C. E., \& Dibner, K. A. (2016). Science literacy: Concepts, contexts, and consequences. Wasington, DC: The National Academies Press.

Stein, R. A., Ometa, O., Pachtman Shetty, S., Katz, A., Ionut Popitiu, M. I., Brotherton, R. Conspiracy theories in the era of COVID19: A tale of two pandemics. International Journal of Clinical Practice, 75(2), e13778.

Takahashi, B., \& Tandoc, E. C. (2016). Media sources, credibility, and perceptions of science: Learning about how people learn about science. Public Understanding of Science, 25(6), https://doi.org/ 10.1177/0963662515574986

Tsai, C. Y., \& Huang, T. C. (2018). The relationship between adult self-efficacy and scientific competencies: The moderating effect of gender. International Journal of Science and Mathematics Education, 16(Suppl 1), 91-106. https://doi.org/10.1007/ s10763-017-9869-4

Tsai, C. Y., Li, Y. Y., \& Cheng, Y. Y. (2017). The relationships among adult affective factors, engagement in science, and scientific competencies. Adult Education Quarterly, 67(1), 30-47. https://doi. org/10.1177/0741713616673148

Tse, D. C., Nakamura, J., \& Csikszentmihalyi, M. (2021). Living well by 'flowing' well; The indirect effect of autotelic personality on well-being through flow experience. The Journal of Positive Psychology, 16(3), 310-321. https://doi.org/10.1080/17439760.2020. 1716055

Van Bavel, J. J., Baicker, K., Boggio, P. S., Capraro, V., Cichocka, A., Cikara, M., Crockett, M. J., Crum, A. J., Douglas, K. M., Druckman, J. N., Drury, J., Dube, O., Ellemers, N., Finkel, E. J., Fowler, J. H., Gelfand, M., Han, S. , Haslam, S. A., Jetten., et al. (2020). Using social and behavioural science to support COVID-19 pandemic response. Nature Human Behaviour, 4(5), 460-471. https:// doi.org/10.1038/s41562-020-0884-Z

Vilia, P., \& Candeias, A. A. (2020). Attitude towards the discipline of physics-chemistry and school achievement: Revisiting factor structure to assess gender differences in Portuguese high-school students. International Journal of Science Education, 42(1), 133150. https://doi.org/10.1080/09500693.2019.1706012 
Wan, Z. H., \& Lee, J. C. K. (2017). Hong Kong secondary school students' attitudes towards science: A study of structural models and gender differences. International Journal of Science Education, 39(5), 507-527. https://doi.org/10.1080/09500693.2017.1292015

Wang, Y. H. (2012). The dominant sex dominates technology? An interpretation of the gendered-technology phenomenon. Chinese Journal of Science Education, 20(3), 241-265. https://doi.org/10. 6173/CJSE.2012.2003.02

Wang, Y. L., \& Tsai, C. C. (2019). Exploring the structure of science learning self-efficacy: The role of science learning hardiness and perceived responses to capitalization attempts among Taiwanese junior high school students. Research in Science \& Technological Education, 37(1), 54-70. https://doi.org/10.1080/02635143. 2018.1480476
Wang, H.-H., Hong, Z. R., Lin, H.-S., \& Tsai, C.-Y. (2020). The effects of adult sustainability attitudes, psychological well-being, nature relatedness and interest in scientific issues. Current Psychology. https://doi.org/10.1007/s12144-020-00708-1

Woods-McConney, A., Oliver, M. C., McConney A, Schibeci, R., \& Maor, D. (2014) Science engagement and literacy: A retrospective analysis for students in Canada and Australia. International Journal of Science Education, 36(10), 1588-1608. 10.110.1080/ 09500693.2013.871658

Publisher's Note Springer Nature remains neutral with regard to jurisdictional claims in published maps and institutional affiliations. 